\title{
Rett syndrome: new clinical and molecular insights
}

In this review, we give a clinical overview of Rett syndrome (RTT), and provide a framework for clinical and molecular approaches to the diagnosis of this severe neurodevelopmental disorder. We also discuss issues that need to be considered in the management of RTT patients, and raise some of the challenges associated with genetic counselling.

\section{In brief}

- Incidence of 1:10000 female births by the age of 12 years

- Severe neurodevelopmental disorder affecting females

- Normal early development is followed by loss of fine and gross motor skills and communication

- Characteristic stereotypic hand movements in most affected individuals

- A number of clinical RTT variants

- Pathogenic mutations in the gene MECP2 have been identified in up to $90-95 \%$ of classical RTT

- MECP2 gene defects can give rise to non-RTT phenotypes

- Pathogenic mutations the genes CDKL5 and possibly Netrin G1 account for a small proportion of cases

- Disease mechanisms remain unclear

- Management is currently symptomatic

\section{Sarah L Williamson ${ }^{1}$ and John Christodoulou ${ }^{*, 2}$}

${ }^{1}$ Western Sydney Genetics Program, the Royal Alexandra Hospital for Children, Sydney, Australia; ${ }^{2}$ Discipline of Paediatrics and Child Health, University of Sydney, Sydney, Australia

European Journal of Human Genetics (2006) 14, 896-903. doi:10.1038/ sj.ejhg. 5201580

Keywords: Rett syndrome; mental retardation; methyl CpG-binding protein 2; MECP2; transcription factor; methylation

*Correspondence: Professor J Christodoulou, Western Sydney Genetics Program, The Children's Hospital at Westmead, Locked Bag 4001, Westmead, 2145, NSW, Australia. Tel: +61 29845 3452;

Fax: + 6129845 1864; E-mail: johnc@chw.edu.au

Received 11 October 2005; revised 5 December 2005; accepted 7 December 2005

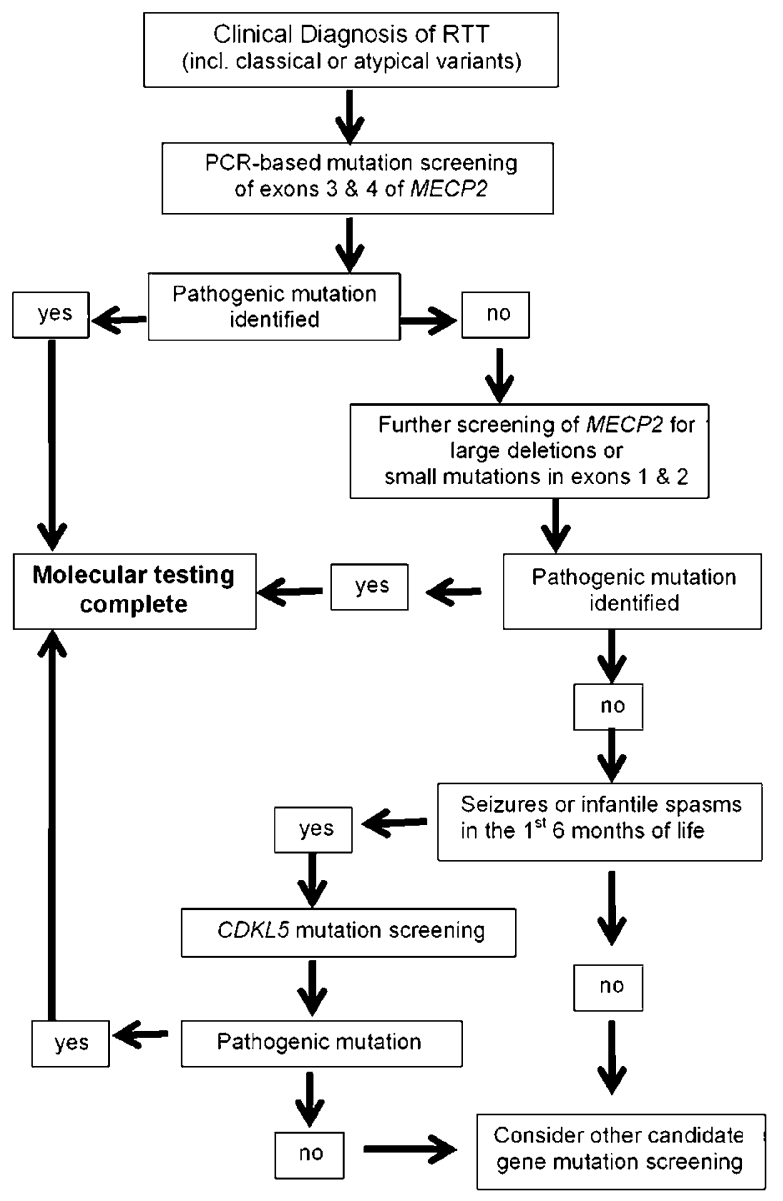

Figure 1 Genetic testing strategy for RTT. Mutation screening of MECP2 exons 3 and 4 is recommended initially followed by exons 1, 2 and MLPA or other methods (to detect large deletions). If a pathogenic mutation is not found, CDKL5 screening is recommended for patients with a severe seizure disorder in the first 6 months of life.

\section{Introduction}

Rett syndrome (RTT; OMIM 312750) is a severe neurodevelopmental disorder primarily affecting females and has an incidence of 1:10000 female births by the age of 
12 years $^{1}$ making it one of the most common genetic causes of severe mental retardation (MR) in females. It is characterised by apparently normal development for the first 6-18 months of life followed by the loss of acquired fine and gross motor skills and the ability to engage in social interaction, and the development of stereotypic hand movements. There is a wide variability in the rate of progression and severity of the disease, and as well as the classical form of RTT there are a number of recognised atypical variants. ${ }^{2,3}$

Mutations in the X-linked gene methyl CpG-binding protein 2 (MECP2) have been found in of the majority of patients, and more recently mutations in two other genes, cyclin-dependent kinase like $5(C D K L 5)^{4-7}$ and Netrin $G 1^{8}$ have been identified in patients with a clinical phenotype that strongly overlaps with RTT (Figure 1).

\section{Clinical synopsis}

Although it was initially believed that the recognisable features of RTT appear after an apparently normal prenatal, perinatal and early infancy period, more recent studies have clearly shown that even in the first 6 months of life the female RTT infant may display subtle behavioural abnormalities. ${ }^{9,10}$ A general stagnation of development is followed by the loss of fine and gross motor skills, social interaction and intellectual functioning. A more definitive clinical picture evolves in stages over a number of years, culminating in motor deterioration and ultimate demise. ${ }^{11}$ The Trevathan diagnostic criteria ${ }^{2}$ were revised in 2001 at a satellite meeting of the European Paediatric Neurology Society, ${ }^{3}$ which has helped in resolving inconsistencies and ambiguities in the categorisation of patients into classical or variant RTT (see Table 1).

It is now clear that females with RTT may have a much broader phenotype than originally described, with a number of variants now described which may be more or less severe than the clinical picture seen in classical RTT. Moreover, it is now known that there exist rare males with a severe neonatal-onset encephalopathy, with prominent breathing abnormalities. ${ }^{12-14}$ In addition, a number of males with a phenotype comparable to females with classical or atypical RTT have been described, some of who also have a 47XXY karyotype, ${ }^{15-17}$ whereas others are mosaic for severe MECP2 mutations, ${ }^{18}$ and still others with MR have MECP2 mutations, which when seen in females are associated with only a much milder phenotype ${ }^{19}$ (for a review $\operatorname{see}^{20}$ ).

\section{Diagnostic approaches}

The diagnosis of RTT remains a clinical one, using criteria such as those outlined in Table 1. In addition, guidelines have been developed to facilitate more consistent descrip-
Table 1 Revised diagnostic criteria for classical and variant $\mathrm{RTT}^{\mathrm{a}}$

Classical RTT

Necessary criteria

1. Normal prenatal and perinatal history

2. Normal psychomotor development for the first 6 months

3. Normal head circumference at birth

4. Postnatal deceleration of head growth in most individuals

5. Loss of purposeful hand skills between 6 months and $2 \frac{1}{2}$ years

6. Hand stereotypies

7. Evolving social withdrawal, communication dysfunction, loss of acquired speech, and cognitive impairment

8. Impairment or deterioration of locomotion

Supportive criteria

1. Breathing disturbances during waking hours

2. Bruxism

3. Impairment of sleeping pattern from early infancy

4. Abnormal muscle tone associated with muscle wasting and dystonia

5. Peripheral vasomotor disturbances

6. Progressive kyphosis or scoliosis

7. Growth retardation

8. Hypotrophic small and cold feet and/or hands

Exclusion criteria

1. Evidence of a storage disorder including organomegaly

2. Cataract, retinopathy, or optic atrophy

3. History of perinatal or postnatal brain damage

4. Confirmed inborn error of metabolism or neurodegenerative disorder

5. Acquired neurological disorder due to severe head trauma or infection

Variant RTT

Inclusion criteria

1. At least three of the six main criteria

2. At least five of the 11 supportive criteria

Main criteria

1. Reduction or absence of hand skills

2. Loss or reduction of speech (including babble)

3. Hand stereotypies

4. Loss or reduction of communication skills

5. Deceleration of head growth from early childhood

6. Regression followed by recovery of interaction

Supportive criteria

1. Breathing irregularities

2. Abdominal bloating or air swallowing

3. Bruxism

4. Abnormal locomotion

5. Kyphosis or scoliosis

6. Lower limb amyotrophy

7. Cold, discoloured and usually hypotrophic feet

8. Night time screaming and other sleep disturbances

9. Inexplicable episodes of screaming or laughing

10. Apparently diminished sensitivity to pain

11. Intense eye contact and/or eye pointing

${ }^{a}$ Modified from Hagberg et al: Eur J Paediatr Neurol 2002; 6: $293-$ 297.

tion of clinical features. ${ }^{21}$ The identification of a MECP2 mutation can support a clinical diagnosis but should not be used as a basis for diagnosis. Further classification into 
whether the individual has classical RTT or one of the recognised variants is of value when coupled with MECP2 mutational findings in terms of allowing potential future genotype-phenotype correlations (see below).

\section{Molecular and genetic basis of RTT Mutations in MECP2}

$M E C P 2$ is an $\mathrm{X}$-linked gene that has two isoforms $M E C P 2 \_$e1 (MECP2- $\alpha$ or MECP2 B form) and MECP2_e2 (MECP2- $\beta$ or MECP2 A form), created by alternative splicing of exon 2 and the use of two alternative start codons. The resulting proteins are almost identical but have alternative N-termini (Figure 2). The MeCP2 protein has two major functional domains the methyl-binding domain (MBD), which binds specifically to DNA at methylated $\mathrm{CpG}^{\prime}$, and a transcription repression domain (TRD) that is responsible for recruiting other proteins that mediated transcription repression (Figure 3). ${ }^{22-26}$ The MECP2_e1 isoform has only recently been described and is the most abundant of the two isoforms. ${ }^{27,28}$

Mutations in MECP2 were first reported in $1999,{ }^{29}$ and subsequent screening of RTT patients has shown that almost $90-95 \%$ of classical RTT have pathogenic mutations. ${ }^{30}$ To date over 200 individual nucleotide changes which cause pathogenic mutations have been described (Figure 4, RettBASE; mecp2.chw.edu.au ${ }^{31}$ and MeCP2.org.uk); however, the eight most commonly occurring missense and nonsense mutations account for almost $70 \%$ of all mutations, and small deletions associated with a deletion hotspot in the C-terminal region of the MeCP2 protein account for an additional $9 \%$ of pathogenic
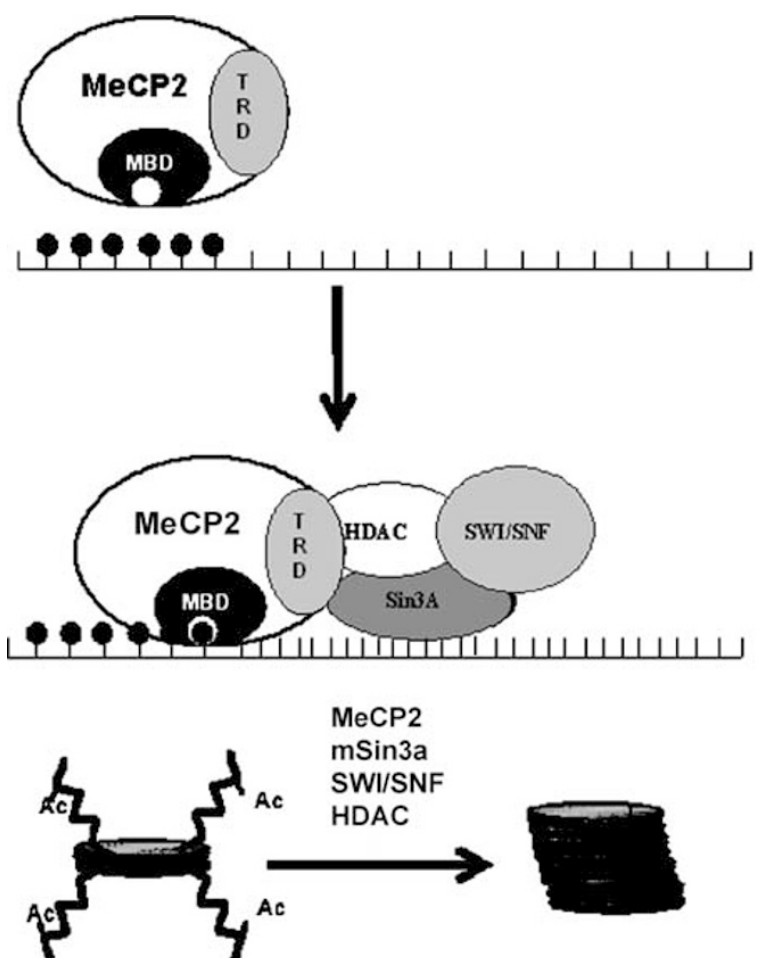

chromatin

accessivle $\&$ active

chromatin

condensed \& inactive

Figure 3 The mechanism of transcription repression by MeCP2. The methyl-binding domain (MBD) of MeCP2 binds specifically to methylated $\mathrm{CpG}$ sites on DNA, the transcription repression domain (TRD) then recruits several corepressor proteins. This results in the deacetylation and condensation of chromatin, which is now not accessible to the transcription machinery. Thus, genes in the region of DNA that MeCP2 binds are not expressed.

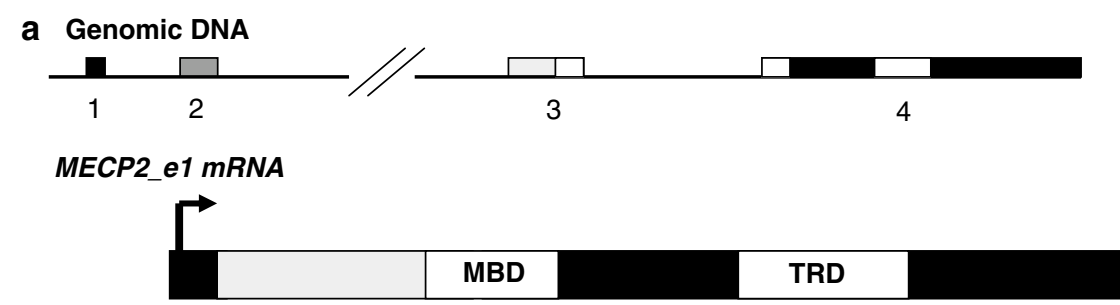

MECP2_e2 mRNA

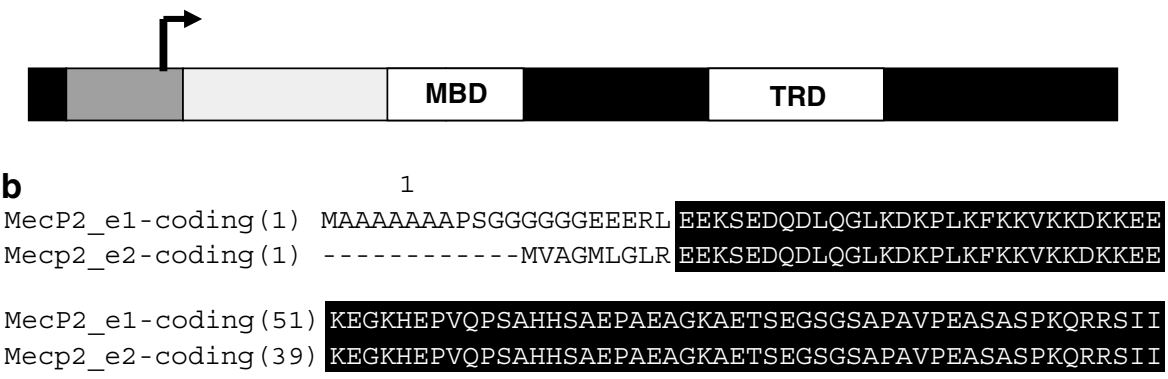

Figure 2 The two MECP2 isoforms. (a) Genomic structure of the two MECP2 isoforms and the two alternative mRNA species produced. The arrows indicate the start codons for each mRNA. (b) An alignment of the first 100 amino acids of MeCP2_e1 with MeCP2_e2 indicating the differences in the $\mathrm{N}$-terminus. 


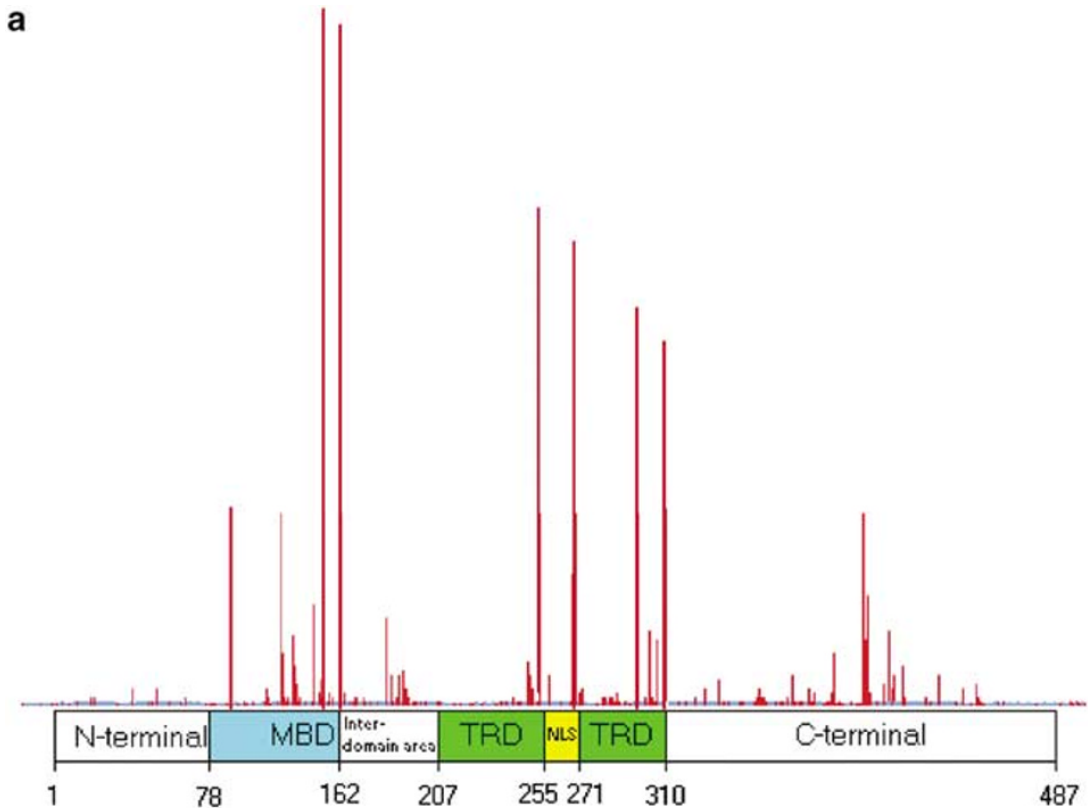

b

\begin{tabular}{|c|c|c|c|}
\hline $\begin{array}{c}\text { Nucleotide } \\
\text { change }\end{array}$ & $\begin{array}{c}\text { Amino acid } \\
\text { change }\end{array}$ & Cases reported & $\begin{array}{c}\text { Percentage (of pathogenic } \\
\text { mutations reported) }\end{array}$ \\
\hline $316 \mathrm{C}>\mathrm{T}$ & $\mathrm{R} 106 \mathrm{~W}$ & 59 & $4.8 \%$ \\
\hline $397 \mathrm{C}>\mathrm{T}$ & $\mathrm{R} 133 \mathrm{C}$ & 67 & $5.4 \%$ \\
\hline $473 \mathrm{C}>\mathrm{T}$ & $\mathrm{T} 158 \mathrm{M}$ & 150 & $12.2 \%$ \\
\hline $502 \mathrm{C}>\mathrm{T}$ & $\mathrm{R} 168 \mathrm{X}$ & 147 & $11.9 \%$ \\
\hline $763 \mathrm{C}>\mathrm{T}$ & $\mathrm{R} 255 \mathrm{X}$ & 132 & $10.7 \%$ \\
\hline $808 \mathrm{C}>\mathrm{T}$ & $\mathrm{R} 270 \mathrm{X}$ & 118 & $9.6 \%$ \\
\hline $880 \mathrm{C}>\mathrm{T}$ & $\mathrm{R} 294 \mathrm{X}$ & 101 & $8.2 \%$ \\
\hline $916 \mathrm{C}>\mathrm{T}$ & $\mathrm{R} 306 \mathrm{C}$ & 79 & $6.4 \%$ \\
\hline $20-100 \mathrm{bp}$ & & 120 & $9.7 \%$ \\
\hline deletions & & 1231 & $78.9 \%$ \\
\hline Total & & & \\
\hline
\end{tabular}

Figure 4 Frequency of pathogenic mutations in MECP2. (a) The position and frequency of reported MECP2 mutations in RettBASE. The numbers refer to the amino-acid position in the MeCP2 protein sequence. (b) Frequency of the most common mutations in RettBASE.

mutations. Mutations are found throughout the gene, and more recently large deletions (kilobases in size) that delete whole exons have also been identified in a proportion of patients who were previously considered to be mutation negative, and are more commonly found in individuals with classical (36\%; 46 out of 128$)$ than atypical (3\%; seven out of 229) RTT cases. ${ }^{32-38}$ On the other hand, pathogenic mutations involving exon 1 appear to be only rarely associated with RTT. ${ }^{30,37,39,40}$ In almost all cases the mutations are de novo, and there is some evidence suggesting that in the majority of cases the mutation has arisen on the paternal $\mathrm{X}$ chromosome. ${ }^{41,42}$
More recently, whole duplications of the MECP2 gene have been associated with severe X-linked MR with progressive spasticity, no or poor speech acquisition and acquired microcephaly, ${ }^{43}$ which has been recapitulated in a mouse model overexpressing MeCP2. ${ }^{44}$ Clinical descriptions of younger patients with duplications or with functional disomy of the Xq28 region have also noted severe hypotonia with or without the development of microcephaly, and interestingly cryptorchidism in males. ${ }^{45-47}$

It is important to note that the identification of a mutation in MECP2 does not necessarily equate to a 
diagnosis of RTT. MECP2 mutations have also been found in other clinical phenotypes, including individuals with an Angelman-like picture, ${ }^{48,49}$ nonsyndromic X-linked $\mathrm{MR},{ }^{50}$ PPM-X syndrome, ${ }^{51}$ autism $^{52}$ and neonatal encephalopathy. ${ }^{13,14,53}$ Males with a neonatal encephalopathy phenotype generally have MECP2 mutations, which when seen in females are associated with more severe RTT. ${ }^{13,14,53}$ Males with a more RTT-like phenotype may also have an Xchromosome aneuploidy ${ }^{15-17}$ or may be mosaic for a MECP2 mutation. ${ }^{18}$ Contrary to earlier studies ${ }^{19,48,50,52}$ recent studies of large cohorts of autistic patients and males with nonspecific MR suggest that pathogenic MECP2 mutations are only rarely observed in these groups of patients. ${ }^{54-56}$

Genotype-phenotype correlations have given conflicting results but generally truncation mutations tend to be more severe than missense mutations. ${ }^{57}$ Genotype-phenotype correlations are complicated by variations in the severity scales used to describe phenotype, although this issue may be resolved if there is consistency in the descriptions used. $^{21}$ In addition, skewing of X-chromosome inactivation may modulate the clinical severity of the disorder, as was seen in a family in which a T158M mutation was seen in a mother who was clinically normal and had completely skewed X-chromosome inactivation favouring the normal allele, and in her daughter with clinically diagnosed RTT and at least one of her sons who died early in life from severe apnoea. ${ }^{12}$

Rather than being a global transcription repressor as initially suspected, MeCP2 may mediate the expression of a subset of specific targets in the brain. There is recent evidence that MeCP2 binds specifically to certain DNA sequences. ${ }^{58}$ Several studies have indeed identified specific MeCP2 targets, including Hairy $2 a,{ }^{24}$ brain-derived neurotrophic factor $(B d n f),{ }^{59,60} \mathrm{Dl} \times 55^{61}$ and $s g k .{ }^{62}$ It is also worth noting that the observation that the features of RTT correlate with the timing of synapse development has lead to the most recent hypothesis that MeCP2 may be responsible for controlling the expression of genes, which control the development and maintenance of synapses, although this remains to be proven. ${ }^{63,64}$

\section{Mutations in other genes}

As stated above, a proportion of individuals with a clinical diagnosis of RTT do not appear to have mutations in the $M E C P 2$ gene. In recent times mutations in two other genes, $C D K L 5^{4-7}$ and Netrin $G,{ }^{8}$ have been shown to be associated a phenotype that strongly overlaps with that seen in RTT.

In virtually all cases reported to date CDKL5 mutations have been associated with an early onset seizure variant of RTT, the so-called Hanefield variant. ${ }^{4-7}$ Recently, evidence was presented, indicating that there may be a direct interaction between CDKL5 and MeCP2 ${ }^{65}$ suggesting that they are a part of a common pathway in the regulation of neuronal cell function, but it remains to be confirmed how this interaction contributes to the pathogenesis of the RTTlike phenotype. Moreover, it is apparent that mutations in this gene account for only a small subset of RTT patients.

Only one case of a Netrin G1 mutation has been described $^{8}$ and so it remains to be established whether there is a direct causal link with RTT and this gene or whether it should be included as a part of systematic genetic testing of MECP2 mutation-negative RTT patients.

\section{Management \\ Treatment and care}

Unfortunately, there are currently no specific treatments that halt or reverse the progression of the disease, and so management is mainly symptomatic and individualised, focussing on aiming to optimise each patient's abilities. A dynamic multidisciplinary approach is most effective, with specialist input from dietitians, physiotherapists, occupational therapists, speech therapists and music therapists. ${ }^{66}$ Attention needs to be paid to scoliosis (seen in about $87 \%$ of patients by the age of 25 years), ${ }^{67}$ and the development of spasticity, ${ }^{68}$ both of which can have a major impact on mobility, and to the development of effective communication strategies for these severely disabled individuals. ${ }^{69}$ Psychosocial support for families is an integral part of the holistic approach to management, and parent support groups, such as the International Rett Syndrome Association (http://www.rettsyndrome.org/), the Rett Syndrome Research Foundation (http:// www.rsrf.org/), and the Rett Syndrome Association UK (http://rettsyndrome.org.uk/) offer immense practical dayto-day support to families.

Pharmacological approaches to managing problems associated with RTT include melatonin for sleep disturbances, $^{70}$ several agents for the control of breathing disturbances, seizures and stereotypic movements, ${ }^{71,72}$ and L-carnitine for general well-being. ${ }^{73}$ RTT patients have an increased risk of life threatening arrhythmias associated with a prolonged QT interval, ${ }^{74}$ and so avoidance of a number of drugs is recommended, including prokinetic agents (eg, cisapride), antipsychotics (eg, thioridazine), tricyclic antidepressants (eg, imipramine), antiarrhythmics (eg, quinidine, sotolol, and amiodarone), anaesthetic agents (eg thiopental and succinylcholine), and antibiotics (eg erythromycin and ketoconazole). In addition, careful evaluation for evidence of central autonomic function using noninvasive methods may be of value in identifying specific patterns of disturbance, and may ultimately lead to specific therapies for this sometimes very distressing set of clinical problems. ${ }^{75}$

Following the report of reduced CSF folate levels in four females with RTT, ${ }^{76}$ Neul analysed CSF from and additional 76 individuals with RTT, but could not reproduce earlier 
findings, and found that supplementation with folinic acid did not lead to any noticeable clinical improvements. ${ }^{77}$ It therefore remains to be established whether cerebral folate deficiency contributes to the pathophysiology of RTT.

\section{Genetic testing strategys}

A recommended screening strategy (Figure 1) is to firstly screen exons 3 and 4 for mutations using PCR-based techniques such as denaturing HPLC and sequencing, as the majority of mutations are seen in this region If no mutation is identified further screening of exons 1 and 2 is recommended. No pathogenic mutations have yet been identified in exon 2, whereas mutations in exon 1 appear to be rare in RTT patients. Large deletions would be missed by most PCR-based screening strategies, and so for individuals in whom no pathogenic mutations have been found by screening exons 1-4 additional screening for large deletions is recommended, which may be achieved by Southern analysis, quantitative PCR of genomic DNA or alternatively Multiplex Ligation Probe Amplification (MLPA), using a commercial MLPA kit that is specifically developed for MECP2 (MCR-Holland).

Finding a pathogenic mutation in a RTT patient can be used to support the clinical findings in that individual. Most, but not all, pathogenic mutations are de novo, so it is recommended that parental DNA is screened for a mutation identified in a proband, and if the mother is found to have a mutation, analysis for skewing of X-chromosome inactivation may be of help in counselling the family. A number of rare polymorphisms have been seen in parents and unaffected siblings, ${ }^{78}$ and available MECP2 locusspecific mutation databases are valuable tools that can be used to distinguish such rare polymorphisms from a truly pathogenic variation.

Patients who are negative for MECP2 mutations and who have a strong clinical diagnosis of RTT, particularly if there are early onset seizures, should be considered for further screening of the CDKL5 gene. However, it should be noted that the identification of any CDKL5 sequence variation should be treated with caution, and that testing of firstdegree relatives would be essential to permit classification of any variation found.

\section{Genetic counselling}

As pathogenic MECP2 mutations in RTT patients are mostly de novo the recurrence risk is low, estimated empirically to be less than one in $300,{ }^{79}$ although gonadal mosaicism cannot be excluded. ${ }^{29,80}$ The option of prenatal screening should be discussed in families with a proband having a pathogenic mutation. The precise type of mutation, its location, and the presence of skewing of Xchromosome inactivation may together help to a certain degree in prognostication of disease severity. ${ }^{66}$

\section{Conclusion}

RTT is notable for marked variability in the severity and progression of the disorder and at least in the early stages can be difficult to diagnose for those not experienced in the disorder. Treatment remains focused on predicting and treating problems as they develop to improve the quality of life of individuals.

Despite the identification of mutations in MECP2 in the majority of RTT patients the pathophysiological basis of the disorder remains unclear. Future research will focus on the identification and characterisation of the molecular pathways controlled by MeCP2, particularly focusing on those involved in the development and maintenance of synapses. It will be interesting to study the possible relationship between MeCP2 and CDKL5. It is hoped that through these combined approaches, specific therapeutic targets may be identified, which ideally would slow or even arrest disease progression altogether, and may yield insights into other neurodevelopmental disorders.

\section{Further reading}

http://mecp2.chw.edu.au and http://www.iscr.ed.ac.uk/ mecp2/

International Rett Syndrome Association (http:// www.rettsyndrome.org/)

The Rett Syndrome Research Foundation (http:// www.rsrf.org/)

Rett Syndrome Association UK (http://www.rettsyndrome.org.uk/) and

Rett Syndrome Australian Research Fund (http:// www.nesher.com.au/rett/menu-02.htm/)

Kerr AM, Ravine D: Review article: breaking new ground with Rett syndrome. I Intellect Disabil Res 2003; 47: 580-587.

Percy AK, Lane JB: Rett syndrome: clinical and molecular update. Curr Opin Pediatr 2004; 16: 670-677.

Caballero IM, Hendrich B: MeCP2 in neurons: closing in on the causes of Rett syndrome. Hum Mol Genet 2005; 14 Suppl 1: R19-R26.

Segawa M, Nomura Y: Rett syndrome. Curr Opin Neurol 2005; 18: 97-104.

Weaving LS, Ellaway CJ, Gecz J, Christodoulou J: Rett syndrome: clinical review and genetic update. J Med Genet 2005; 42: 1-7.

\section{References}

1 Leonard H, Bower C, English D: The prevalence and incidence of Rett syndrome in Australia. Eur Child Adolesc Psychiatry 1997; 6 (Suppl 1): 8-10.

2 Trevathan E, Moser HW, Opitz JM et al: Diagnostic criteria for Rett syndrome. The Rett Syndrome Diagnostic Criteria Work Group. Ann Neurol 1988; 23: 425-428.

3 Hagberg B, Hanefeld F, Percy A, Skjeldal O: An update on clinically applicable diagnostic criteria in Rett syndrome. Comments to Rett Syndrome Clinical Criteria Consensus Panel 
Satellite to European Paediatric Neurology Society Meeting, Baden Baden, Germany, 11 September 2001. Eur J Paediatr Neurol 2002; 6: 293-297.

4 Tao J, Van Esch H, Hagedorn-Greiwe $M$ et al: Mutations in the $\mathrm{X}$-linked cyclin-dependent kinase-like 5 (CDKL5/STK9) gene are associated with severe neurodevelopmental retardation. Am J Hum Genet 2004; 75: 1149-1154.

5 Weaving LS, Christodoulou J, Williamson SL et al: Mutations of CDKL5 cause a severe neurodevelopmental disorder with infantile spasms and mental retardation. Am J Hum Genet 2004; 75: 1079-1093.

6 Evans JC, Archer HL, Colley JP et al: Early onset seizures and Rettlike features associated with mutations in CDKL5. Eur J Hum Genet 2005; 13: 1113-1120.

7 Scala E, Ariani F, Mari F et al: CDKL5/STK9 is mutated in Rett syndrome variant with infantile spasms. J Med Genet 2005; 42: $103-107$.

8 Borg I, Freude K, Kubart S et al: Disruption of Netrin G1 by a balanced chromosome translocation in a girl with Rett syndrome. Eur J Hum Genet 2005; 13: 921-927.

9 Burford B, Kerr AM, Macleod HA: Nurse recognition of early deviation in development in home videos of infants with Rett disorder. J Intellect Disabil Res 2003; 47: 588-596.

10 Einspieler C, Kerr AM, Prechtl HF: Is the early development of girls with rett disorder really normal? Pediatr Res 2005; 57 (Part 1): 696-700.

11 Hagberg B, Witt-Engerstrom I: Rett syndrome: a suggested staging system for describing impairment profile with increasing age towards adolescence. Am J Med Genet Suppl 1986; 1: $47-59$.

12 Villard L, Kpebe A, Cardoso C, Chelly PJ, Tardieu PM, Fontes M: Two affected boys in a Rett syndrome family: clinical and molecular findings. Neurology 2000; 55: 1188-1193.

13 Wan M, Lee SS, Zhang X et al: Rett syndrome and beyond: recurrent spontaneous and familial MECP2 mutations at CpG hotspots. Am J Hum Genet 1999; 65: 1520-1529.

14 Ben-Zeev B, Yaron Y, Schanen NC et al: Rett syndrome: clinical manifestations in males with MECP2 mutations. J Child Neurol 2002; 17: 20-24.

15 Leonard H, Silberstein J, Falk R et al: Occurrence of Rett syndrome in boys. J Child Neurol 2001; 16: 333-338.

16 Schwartzman JS, Bernardino A, Nishimura A, Gomes RR, Zatz M: Rett syndrome in a boy with a 47, XXY karyotype confirmed by a rare mutation in the MECP2 gene. Neuropediatr 2001; 32: 162-164.

17 Hoffbuhr K, Devaney JM, LaFleur B et al: MeCP2 mutations in children with and without the phenotype of Rett syndrome. Neurology 2001; 56: 1486-1495.

18 Clayton-Smith J, Watson P, Ramsden S, Black GC: Somatic mutation in MECP2 as a non-fatal neurodevelopmental disorder in males. Lancet 2000; 356: 830-832.

19 Orrico A, Lam C, Galli L et al: MECP2 mutation in male patients with non-specific X-linked mental retardation. FEBS Lett 2000; 481: $285-288$

20 Miltenberger-Miltenyi G, Laccone F: Mutations and polymorphisms in the human methyl CpG-binding protein MECP2. Human Mutat 2003; 22: 107-115.

21 Kerr AM, Nomura Y, Armstrong D et al: Guidelines for reporting clinical features in cases with MECP2 mutations. Brain Dev 2001; 23: $208-211$.

$22 \mathrm{Nan} \mathrm{X}, \mathrm{Ng} \mathrm{HH}$, Johnson CA et al: Transcriptional repression by the methyl-CpG-binding protein $\mathrm{MeCP} 2$ involves a histone deacetylase complex. Nature 1998; 393: 386-389.

23 Jones PL, Veenstra GJ, Wade PA et al: Methylated DNA and $\mathrm{MeCP} 2$ recruit histone deacetylase to repress transcription. Nature Genet 1998; 19: 187-191.

24 Stancheva I, Collins AL, Van den Veyver IB, Zoghbi H, NMeehan RR: A mutant form of MeCP2 protein associateed with human rett syndrome cannot be displaced from methylated DNA by Notch in Xenopus embryos. Molec Cell 2003; 12: $425-435$
25 Kokura K, Kaul SC, Wadhwa R et al: The Ski protein family is required for MeCP2-mediated transcriptional repression. $J$ Biol Chem 2001; 276: 34115-34121.

26 Harikrishnan KN, Chow MZ, Baker EK et al: Brahma links the SWI/SNF chromatin-remodeling complex with MeCP2-dependent transcriptional silencing. Nat Genet 2005; 37: 254-264.

27 Mnatzakanian GN, Lohi $\mathrm{H}$, Munteanu I et al: A previously unidentified MECP2 open reading frame defines a new protein isoform relevant to Rett syndrome. Nature Genet 2004; 36: 339-341.

28 Kriaucionis S, Bird A: The major form of MeCP2 has a novel Nterminus generated by alternative splicing. Nucleic Acid Res 2004; 32: $1818-1823$

29 Amir RE, Van den Veyver IB, Wan M, Tran CQ, Francke U, Zoghbi HY: Rett syndrome is caused by mutations in X-linked MECP2, encoding methyl-CpG-binding protein 2. Nature Genet 1999; 23: $185-188$.

30 Amir RE, Fang P, Yu Z et al: Mutations in exon 1 of MECP2 are a rare cause of Rett syndrome. J Med Genet 2005; 42: e15.

31 Christodoulou J, Grimm A, Maher T, Bennetts B: RettBASE: The IRSA MECP2 variation database-a new mutation database in evolution. Human Mutat 2003; 21: 466-472.

32 Schollen E, Smeets E, Deflem E, Fryns JP, Matthijs G: Gross rearrangements in the MECP2 gene in three patients with Rett syndrome: implications for routine diagnosis of Rett syndrome. Hum Mutat 2003; 22: 116-120.

33 Ariani F, Mari F, Pescucci C et al: Real-time quantitative PCR as a routine method for screening large rearrangements in Rett syndrome: Report of one case of MECP2 deletion and one case of MECP2 duplication. Hum Mutat 2004; 24: 172-177.

34 Laccone F, Junemann I, Whatley $\mathrm{S}$ et al: Large deletions of the MECP2 gene detected by gene dosage analysis in patients with Rett syndrome. Hum Mutat 2004; 23: 234-244.

35 Archer HL, Whatley SD, Evans JC et al: Gross rearrangements of the MECP2 gene are found in both classical and atypical Rett Syndrome. J Med Genet 2005, (published online 14th October 2005).

36 Huppke P, Ohlenbusch A, Brendel C, Laccone F, Gartner J: Mutation analysis of the HDAC 1, 2, 8 and CDKL5 genes in Rett syndrome patients without mutations in MECP2. Am J Med Genet A 2005; 137A: 136-138.

37 Ravn K, Nielsen JB, Skjeldal OH, Kerr A, Hulten M, Schwartz M: Large genomic rearrangements in MECP2. Hum Mutat 2005; 25: 324.

38 Shi J, Shibayama A, Liu Q et al: Detection of heterozygous deletions and duplications in the MECP2 gene in Rett syndrome by robust dosage PCR (RD-PCR). Hum Mutat 2005; 25: 505.

39 Evans JC, Archer HL, Whatley SD, Kerr A, Clarke A, Butler R: Variation in exon 1 coding region and promoter of MECP2 in Rett syndrome and controls. Eur J Hum Genet 2004; 13: 124-126.

40 Poirier K, Francis F, Hamel B et al: Mutations in exon 1 of MECP2B are not a common cause of X-linked mental retardation in males. Eur J Hum Genet 2005; 13: 523-524.

41 Girard M, Couvert P, Carrie A et al: Parental origin of de novo MECP2 mutations in Rett syndrome. Eur J Hum Genet 2001; 9: 231-236.

42 Trappe R, Laccone F, Cobilanschi J et al: MECP2 mutations in sporadic cases of Rett syndrome are almost exclusively of paternal origin. Am J Hum Genet 2001; 68: 1093-1101.

43 Van Esch H, Bauters M, Ignatius J et al: Duplication of the MECP2 region is a frequent cause of severe mental retardation and progressive neurological symptoms in males. Am J Hum Genet 2005; 77: 442-453.

44 Collins AL, Levenson JM, Vilaythong AP et al: Mild overexpression of MeCP2 causes a progressive neurological disorder in mice. Hum Mol Genet 2004; 13: 2679-2689.

45 Lachlan KL, Collinson MN, Sandford ROC, van Zyl B, Jacobs PA, Thomas NS: Functional disomy resulting from duplications of distal Xq in four unrelated patients. Hum Genet 2004; 115: 399-408. 
46 Meins M, Lehmann J, Gerresheim F et al: Submicroscopic duplication in Xq28 causes increased expression of the MECP2 gene in a boy with severe mental retardation and features of Rett syndrome. J Med Genet 2005; 42: e12.

47 Slanaville D, Prieur M, de Blois M-C et al: Functional disomy of the Xq28 chromosome region. Eur J Hum Genet 2005; 13: $579-585$.

48 Imessaoudene B, Bonnefont JP, Royer G et al: MECP2 mutation in non-fatal, non-progressive encephalopathy in a male. J Med Genet 2001; 38: 171-174.

49 Watson P, Black G, Ramsden S et al: Angelman syndrome phenotype associated with mutations in MECP2, a gene encoding a methyl CpG binding protein. J Med Genet 2001; 38: 224-228.

50 Couvert $\mathrm{P}$, Bienvenu T, Aquaviva $\mathrm{C}$ et al: MECP2 is highly mutated in X-linked mental retardation. Hum Mol Genet 2001; 10: 941-946.

51 Klauck SM, Lindsay S, Beyer KS, Splitt M, Burn J, Poustka A: A mutation hot spot for nonspecific X-linked mental retardation in the MECP2 gene causes the PPM-X syndrome. Am J Hum Genet 2002; 70: 1034-1037.

52 Carney RM, Wolpert CM, Ravan SA et al: Identification of MeCP2 mutations in a series of females with autistic disorder. Pediatr Neurol 2003; 28: 205-211.

53 Villard L, Levy N, Xiang F et al: Segregation of a totally skewed pattern of $\mathrm{X}$ chromosome inactivation in four familial cases of Rett syndrome without MECP2 mutation: implications for the disease. J Med Genet 2001; 38: 435-442.

54 Yntema HG, Kleefstra T, Oudakker AR et al: Low frequency of MECP2 mutations in mentally retarded males. Eur J Hum Genet 2002; 10: 487-490.

55 Lobo-Menendez F, Sossey-Alaoui K, Bell JM et al: Absence of MeCP2 mutations in patients from the South Carolina autism project. Am J Med Genet 2003; 117B: 97-101.

56 Beyer KS, Blasi F, Bacchelli E et al: Mutation analysis of the coding sequence of the MECP2 gene in infantile autism. Human Genet 2002; 111: 305-309.

57 Schanen C, Houwink EJ, Dorrani N et al: Phenotypic manifestations of MECP2 mutations in classical and atypical Rett syndrome. Am I Med Genet 2004; 126A: 129-140.

58 Klose RJ, Sarraf SA, Schmiedeberg L, McDermott SM, Stancheva I, Bird AP: DNA binding selectivity of MeCP2 due to a requirement for A/T sequences adjacent to methyl-CpG. Mol Cell 2005; 19: $667-678$.

59 Chen WG, Chang Q, Lin Y et al: Derepression of BDNF transcription involves calcium-dependent phosphorylation of MeCP2. Science 2003; 302: 885-889.

60 Martinowich K, Hattori D, Wu H et al: DNA methylation-related chromatin remodeling in activity-dependent BDNF gene regulation. Science 2003; 302: 890-893.

61 Horike S, Cai S, Miyano M, Cheng JF, Kohwi-Shigematsu T: Loss of silent-chromatin looping and impaired imprinting of DLX5 in Rett syndrome. Nat Genet 2005; 37: 31-40.

62 Nuber UA, Kriaucionis S, Roloff TC et al: Up-regulation of glucocorticoid-regulated genes in a mouse model of Rett syndrome. Hum Mol Genet 2005; 14: 2247-2256.
63 Kishi N, Macklis JD: MECP2 is progressively expressed in postmigratory neurons and is involved in neuronal maturation rather than cell fate decisions. Mol Cell Neurosci 2004; 27: 306-321.

64 Shahbazian MD, Antalffy B, Armstrong DL, Zoghbi HY: Insight into Rett syndrome: MeCP2 levels display tissue- and cell-specific differences and correlate with neuronal maturation. Hum Mol Genet 2002; 11: 115-124.

65 Mari F, Azimonti S, Bertani I et al: CDKL5 belongs to the same molecular pathway of MeCP2 and it is responsible for the early seizure variant of Rett syndrome. Hum Mol Genet 2005; 14: $1935-1946$

66 Weaving LS, Ellaway CJ, Gecz J, Christodoulou J: Rett syndrome: clinical review and genetic update. J Med Genet 2005; 42: 1-7.

67 Kerr AM, Webb P, Prescott RJ, Milne Y: Results of surgery for scoliosis in Rett syndrome. J Child Neurol 2003; 18: 703-708.

68 Budden SS: Rett syndrome: habilitation and management reviewed. Eur Child Adolesc Psychiatry 1997; 6 (Suppl 1): 103-107.

69 Ryan D, McGregor F, Akermanis M, Southwell K, Ramke M, Woodyatt G: Facilitating communication in children with multiple disabilities: three case studies of girls with Rett syndrome. Disabil Rehabil 2004; 26: 1268-1277.

70 McArthur AJ, Budden SS: Sleep dysfunction in Rett syndrome: a trial of exogenous melatonin treatment. Dev Med Child Neurol 1998; 40: 186-192.

71 Goyal M, O'Riordan MA, Wiznitzer M: Effect of topiramate on seizures and respiratory dysrhythmia in Rett syndrome. $J$ Child Neurol 2004; 19: 588-591.

72 Percy AK: Clinical trials and treatment prospects. Mental Retard Dev Disab Res Rev 2002; 8: 106-111.

73 Ellaway C, Williams K, Leonard H, Higgins G, Wilcken B, Christodoulou J: Rett syndrome: randomized controlled trial of L-carnitine. I Child Neurol 1999; 14: 162-167.

74 Sekul EA, Moak JP, Schultz RJ, Glaze DG, Dunn JK, Percy AK: Electrocardiographic findings in Rett syndrome: an explanation for sudden death? J Pediatr 1994; 125: 80-82.

75 Julu POO: The central autonomic disturbance in Rett syndrome in Kerr A and Witt-Engerstrom I (eds): Rett Disorder and the Developing Brain. Oxford: Oxford University Press, 2001, pp 131-181.

76 Ramaekers VT, Hansen SI, Holm J et al: Reduced folate transport to the CNS in female Rett patients. Neurology 2003; 61: 506-515.

77 Neul JL, Maricich SM, Islam M et al: Spinal fluid 5-methyltetrahydrofolate levels are normal in Rett syndrome. Neurology 2005; 64: 2151-2152.

78 Buyse IM, Fang P, Hoon KT, Amir RE, Zoghbi HY, Roa BB Diagnostic testing for Rett syndrome by DHPLC and direct sequencing analysis of the MECP2 gene: identification of several novel mutations and polymorphisms. Am J Hum Genet 2000; 67: $1428-1436$

79 Killian W: On the genetics of Rett syndrome: analysis of family and pedigree data. Am J Med Genet Suppl 1986; 1: 369-376.

80 Mari F, Caselli R, Russo S et al: Germline mosaicism in Rett syndrome identified by prenatal diagnosis. Clin Genet 2005; 67 : 258-260. 